\title{
Epitaxial mineral growth in fluid inclusions monitors redox equilibria in subducting ultramafic rocks
}

\author{
NADIA MALASPINA* ${ }^{1}$, MARCELLO CAMPIONE ${ }^{1}$, MATTIA \\ LA FORTEZZA $^{1}$ AND MARCO SCAMBELLURI ${ }^{2}$ \\ ${ }^{1}$ Department of Earth and Environmental Sciences, University \\ of Milano-Bicocca, Piazza della Scienza 4, Milano, Italy \\ (*correspondence: nadia.malaspina@unimib.it) \\ ${ }^{2}$ Department of Earth, Environmental and Life Sciences, \\ University of Genova, Corso Europa 26, Genova, Italy
}

The redox processes affecting subducting slabs and the redox potential of slab-derived fluids are poorly constrained. Magnetite-bearing multiphase inclusions hosted in metamorphic olivine in harzburgites from the Almirez Complex (Bétic Cordillera, Spain) represent remnants of the aqueous fluid produced by dehydration of former serpentinites at P-T conditions of $650-700{ }^{\circ} \mathrm{C}$ and $2 \mathrm{GPa}$ during subduction [1]. Through single-crystal X-ray diffraction here we show the epitaxial growth of magnetite on the host olivine by sharing planes along (111) and (100), respectively. Preliminary $\mu$-raman spectroscopy also indicates the occurrence of Mg-cummingtonite, orthopyroxene, \pm chondrodite daughter crystals, in equilibrium with magnetite within the inclusions. This mineral assemblage corresponds to a univariant curve in a $\mathrm{fO}_{2}$-T diagram for the MFSH system, buffering the redox conditions of the fluid-olivine interaction at high pressure for $\mathrm{fO}_{2}=\mathrm{NNO}+4$ [2].

The exceptional occurrence of commensurism between magnetite and olivine lattices acts as an efficient driving force for the selective nucleation and growth of the magnetite micro-crystals within the inclusions. This driving force likely allowed to overtake energy barriers related to the necessity to concentrate $\mathrm{Fe}^{3+}$ within the inclusion microcavity through migration of $\mathrm{Fe}^{2+}$ from the olivine host and its oxidation by supercritical water inside the inclusion. This suggests that magnetite and the chemical conditions imposed by its formation control the development of the other solid daughter phases within the Almirez multiphase inclusions. The fluidolivine interaction investigated in this work may be considered as a proxy for the fluid-mediated redox reaction in an olivine rich $(>80 \mathrm{vol} \%)$ slab-mantle interface at high flluid/rock ratios.

REFERENCES

[1] Scambelluri, Bottazzi, Trommsdorff, Vannucci, Hermann, Gomez-Pugnaire \& Lopez-Sanchez Vizcaino (2001) Earth and Planet Sci Lett 192, 457-470

[2] Evans \& Ghiorso (1995) Am Mineral 80, 649-663 